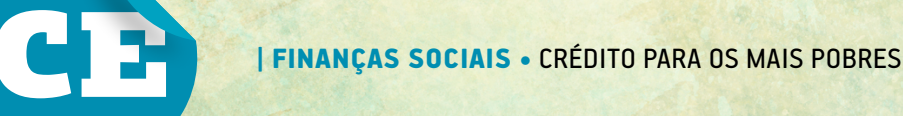
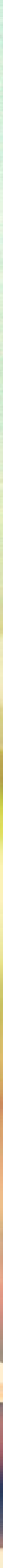


\section{CRÉDITO PARA OS MAIS POBRES}

| POR ARIÁDNE SCALFONI RIGO

\section{Criados por organizações locais, os bancos comunitários estabeleceram uma metodologia própria para oferecer produtos e serviços financeiros à população de baixa renda.}

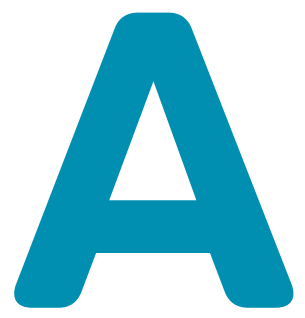

pesar do aumento do acesso ao crédito na última década no Brasil, vários aspectos ainda distanciam as pessoas mais pobres das carteiras de crédito dos bancos comerciais. Entre esses aspectos, destacam-se: o fato de serem muito pobres e terem sua capacidade de pagamento reduzida; os trâmites burocráticos típicos desses processos; e a inadequação dos produtos financeiros para a população de baixa renda.

No Programa Nacional do Microcrédito Produtivo Orientado (PNMPO), por exemplo, entre as quase nove milhões de pessoas que compõem o público-alvo, pouco mais de $8 \%$ tiveram acesso aos empréstimos. Os bancos tradicionais não contam com metodologias para atender à camada mais pobre da população.

No universo das microfinanças, são as organizações comunitárias que vêm desenvolvendo essas metodologias, por meio das finanças solidárias ou de proximidade. As organizações locais têm a capacidade de se inserirem na teia de relações locais e de oferecerem produtos e serviços financeiros mais adequados à população de baixa renda.

Entre essas organizações, estão os bancos comunitários de desenvolvimento (BCDs), como o Banco Palmas. Em 1998, os moradores do Conjunto Palmeiras, na periferia de Fortaleza, Ceará, elaboraram um sistema de concessão de crédito de pequeno valor para ajudá-los a enfrentar a pobreza. O propósito da criação do banco comunitário era aumentar a circulação da riqueza no bairro, ofertando crédito para os moradores.

Em 2003, o Banco Palmas criou seu próprio Instituto (Instituto Banco Palmas), para formalizar parcerias com instituições públicas e privadas e reaplicar a experiência em outros territórios. Desde então, uma rede brasileira de bancos comunitários vem se constituindo. Em 2009, eram 49 BCDs; no fim de 2013, 103. Hoje, são ao menos 155 BCDs espalhados pelo país. São 67 na Região Nordeste, 53 na Região Norte, 26 no Sudeste, sete na Região Centro-Oeste e dois no Distrito Federal.

\section{COMO OS BANCOS COMUNITÁRIOS FUNCIONAM?}

Entre as particularidades do modo de funcionamento dos bancos comunitários, quatro podem ser destacadas: a gestão coletiva; a oferta de linhas de crédito; os mecanismos sociais de controle; e o uso de moedas sociais.

\section{Gestão coletiva}

As decisões e a gestão das atividades nos BCDs são conduzidas em espaços de discussão envolvendo os membros da comunidade. Essa particularidade é percebida logo no processo de implementação do BCD, momento em que a manifestação coletiva do interesse da comunidade por 


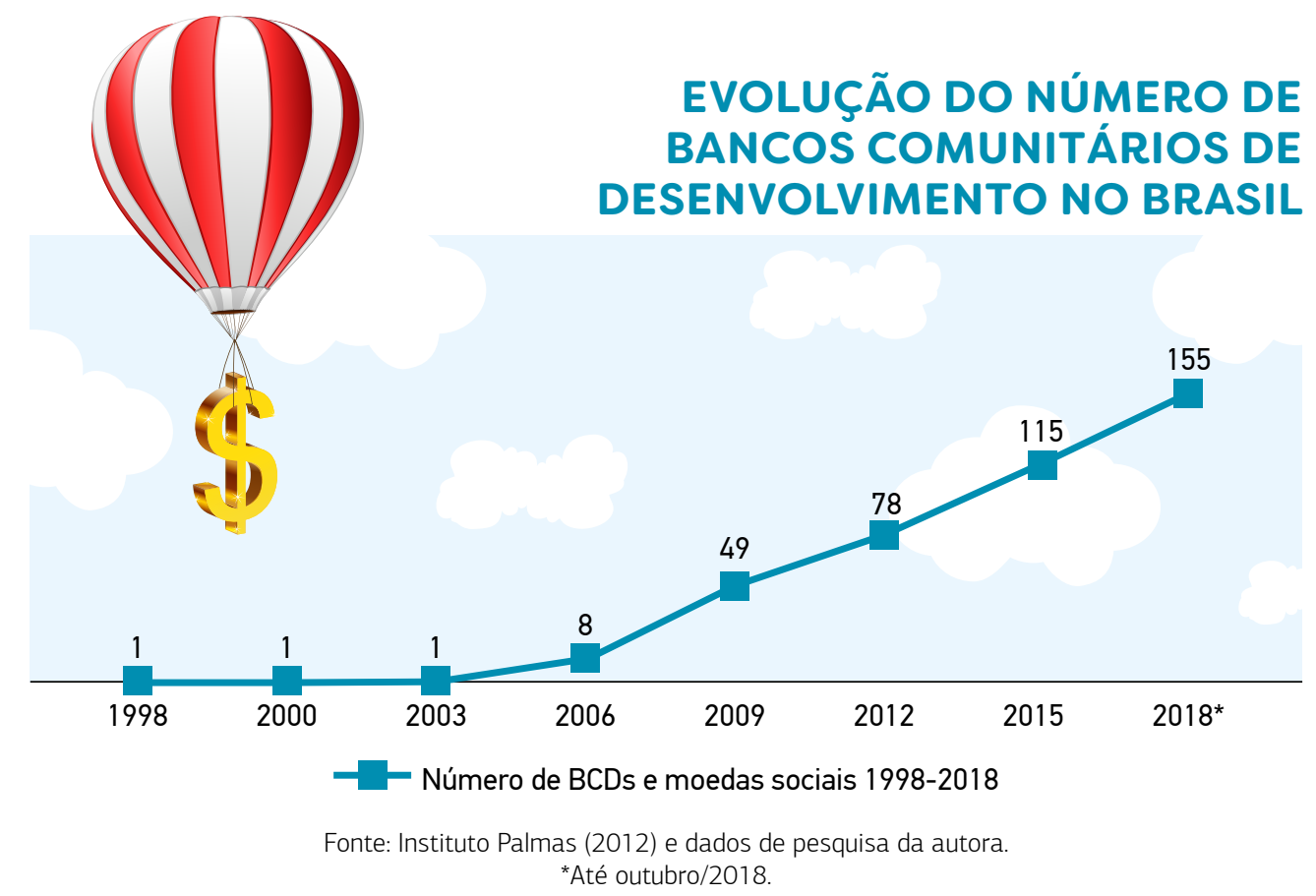

empreender a iniciativa orienta o processo. A partir daí, espaços de discussão são propostos e passam a fazer parte da consolidação da experiência. Normalmente, são constituídos pelo menos dois espaços de gestão coletiva: o Conselho Gestor e o Comitê de Análise de Crédito (CAC). Suas composições e representações são definidas pelos membros da comunidade envolvidos no processo.

Ao longo do caminho de consolidação do banco comunitário, o Conselho Gestor organiza assembleias e reuniões com lideranças comunitárias e representantes de organizações locais e de outras parceiras do BCD. Nesses encontros, são traçadas diretrizes e tomadas decisões vinculadas às ações do BCD de ordem mais ampla, como novas parcerias, captação de recursos etc. Já o CAC é um grupo composto de membros do BCD denominados de agentes de crédito, mas também pode contar com lideranças e representantes do território. Sua tarefa é reunir-se para discutir e decidir sobre as solicitações de crédito demandadas.

\section{Oferta de linhas de crédito}

As linhas de crédito mais comuns dos bancos comunitários são crédito produtivo e crédito para consumo. $\mathrm{O}$ crédito produtivo é direcionado ao apoio de micro, pequenos e médios empreendimentos, individuais ou coletivos, possui juros baixos (de 1 a 2,5\% ao ano) e é ofertado em real. O intuito é possibilitar a geração de renda e oportunidades de
Em 2009, existiam 49 bancos comunitários no Brasil. Hoje, já são ao menos 155 espalhados pelo país. São 67 na Região Nordeste, 53 na Região Norte, 26 no Sudeste, sete na Região Centro-Oeste e dois no Distrito Federal.

trabalho para a comunidade. O crédito para consumo destina-se a empréstimos de pequena monta, de caráter de urgência, sem juros e oferecido em moeda social. A intenção de usar moeda própria é estimular o consumo na comunidade.

\section{Mecanismos sociais de controle}

O julgamento das solicitações de crédito e sua eventual cobrança fundamentam-se num mecanismo social de controle entre os membros da comunidade, e não no formalismo regido por legislações e papelada. Nesse processo, a sensibilidade dos agentes de crédito e sua relação com a vizinhança são importantes, pois informam o CAC sobre as 


\section{No intuito de estimular a produção e o consumo local, o banco comunitário cria e mantém no território uma moeda social que circula apenas entre os moradores e empreendimentos da comunidade.}

especificidades dos pedidos, e este toma a decisão de emprestar ou não. Interessante notar que o BCD geralmente não considera a inadimplência do solicitante em outros bancos ou nos sistemas comuns de proteção ao crédito (Serviço de Proteção ao Crédito - SPC - ou Serasa, por exemplo). A ênfase do BCD está nas relações comunitárias.

\section{Uso de moedas sociais}

No intuito de estimular a produção e o consumo local, o BCD cria e mantém no território uma moeda social que circula apenas entre os moradores e empreendimentos da comunidade. Essas moedas desempenham papel importante não apenas econômico (na circulação interna da riqueza), mas também identitário e pedagógico. O uso da moeda social envolve a noção de apropriação cidadã da moeda, a história e a identidade do lugar.

\section{QUAIS SÃO OS DESAFIOS?}

A criação e consolidação dos BCDs dependem, em boa medida, das entidades de apoio e fomento (EAFs). São organizações não governamentais (ONGs), associações e incubadoras universitárias com expertise na metodologia de funcionamento dos BCDs. Algumas EAFs conhecidas e que estão envolvidas na rede brasileira de $\mathrm{BCDs}$ são: o próprio Instituto Banco Palmas, a Incubadora Tecnológica de Economia Solidária e Gestão do Desenvolvimento Territorial da Escola de Administração da Universidade Federal da Bahia (ITES/EAUFBA), o Núcleo de Apoio às Atividades de Cultura e Extensão em Economia Solidária da Universidade de São Paulo (Nesol-USP) e a ONG Ateliê de Ideias, do Espírito Santo.

A falta de fundo de crédito está entre os principais desafios dos BCDs. A maioria dos BCDs depende do apoio técnico e do aporte financeiro que as EAFs oferecem, da participação em editais públicos e da construção de parcerias com investidores públicos e privados. A sustentabilidade de um banco comunitário depende sobremaneira da rede de parceiros que consegue construir ao longo da sua trajetória.
Muitos arranjos institucionais podem ser feitos para suportar técnica e financeiramente os BCDs. Governos locais têm apoiado essas iniciativas, geralmente via EAFs, tendo em vista o potencial de combate à pobreza. Um exemplo é o Banco dos Cocais, criado em 2007 por iniciativa da prefeitura de São João do Arraial, no Piaú, e do Instituto Banco Palmas. Hoje em dia, o banco é o único meio de acesso a serviços financeiros pela população do município. Quase 30 mil moedas sociais Cocais circulam, por mês, entre as mãos de comerciantes, produtores rurais e moradores, dinamizando a circulação da riqueza no território.

Organizações privadas também vêm apoiando projetos das EAFs como parte das suas ações de responsabilidade social. Por exemplo, há mais de oito anos, a Dow Química suporta parte das ações da ITES/EAUFBA, na comunidade de Matarandiba e na consolidação do Banco Comunitário Ilhamar. O importante nesses arranjos é cuidar para que seus objetivos não se desvinculem dos princípios de funcionamento dos BCDs direcionados à inclusão e participação dos mais pobres e ao desenvolvimento das suas comunidades.

As experiências dos BCDs no Brasil mostram o potencial dessas iniciativas para oferecer serviços financeiros às pessoas mais pobres. Foram 100 novos BCDs criados entre $2008 \mathrm{e}$ 2015. De lá para cá, mesmo com as dificuldades que as EAFs têm enfrentado para obtenção de recursos, mais de 40 novos BCDs foram criados. No entanto, para que os BCDs atuem de forma mais efetiva e abrangente nos territórios onde estão inseridos, é preciso construir um marco legal apropriado às finanças solidárias e propiciar arranjos e parcerias para que as iniciativas consigam se desenvolver.

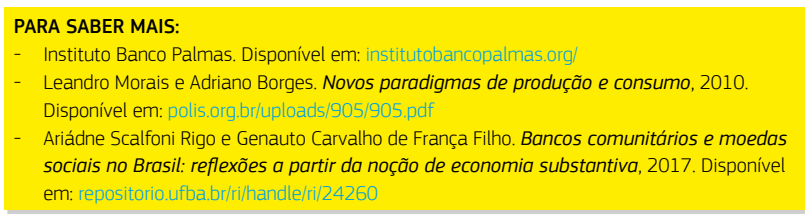

ARIÁDNE SCALFONI RIGO > Professora da Universidade Federal da Bahia > ariadne.rigo@ufba.br 